\title{
Impact of the Artificial Surfaces Sunk on the Global Warming by the Absorption of the Solar Radiation and the Albedo Coefficient Modification
}

\section{Romdhane Ben Slama}

Higher Institute of Applied Sciences and Technology of Gabes (ISSAT), University of Gabes, Tunisia

*Corresponding author: Slama BR, Higher Institute of Applied Sciences and Technology of Gabes (ISSAT), University of Gabes, Tunisia, Tel: +21675392108; Email:Romdhaneb.slama@gmail.com

Received Date: November 23, 2017; Accepted Date: May 16, 2018; Published Date: May 20, 2018

Copyright: ( 2018 Slama BR. This is an open-access article distributed under the terms of the Creative Commons Attribution License, which permits unrestricted use, distribution, and reproduction in any medium, provided the original author and source are credited.

\begin{abstract}
In this article, is implicated another factor that greenhouse gases in global warming. Indeed, $\mathrm{CO}_{2}$ and its equivalents retain only infrared radiation of long wavelengths. These are issued naturally by the earth since always, but recently under the pretext of prestige or fashion, in hot countries is added the paintings of buildings in dark color, black in this case. These colors affect the albedo coefficient by the absorption of solar radiation and the emission of far infrared radiation that cannot cross the greenhouse gases, so partly reflected towards the earth causing global warming. Global action on reducing greenhouse gas emissions should therefore be complemented by a reduction in the dark color areas created by man.
\end{abstract}

Keywords: Global warming; Greenhouse effect; Infrared radiation Emittance; Dark color; Hot country

\section{Introduction}

\section{Global warming seen by a solar energy expert}

Specialists in the thermal conversion of solar energy are well aware that a solar air or water collector consists mainly of all of the following elements: a black absorber, glazing, insulation and trunk. For this to heat up and rise in temperature, it is first necessary to absorb the incident solar radiation, then to save the heat comes the role of the insulator on the back side of the collector and glazing on the front side. The latter must be selective i.e. be transparent to the incident solar light of short wavelength and opaque to the far infrared radiation emitted by the absorber of the solar collector. On the side of global warming, it is well known that $\mathrm{CO}_{2}$ is a greenhouse gas. It is less known that greenhouse gases allow almost all of the radiation from the sun to pass but are almost opaque to far infrared radiation from the earth. On the other hand, we do not differentiate the origin of the infrared radiation emitted by the surface of the earth.

We distinguish a) the infrared radiation emitted by the surface of the Earth's crust and which serves to create a greenhouse effect necessary to maintain a favourable temperature to life on earth, b) the infrared radiation emitted by the dark artificial surfaces that absorb the solar radiation and re-emit it into the far-infrared spectrum, to which the greenhouse gases are opaque. Examples include paved roads, roadways, sidewalks, buildings and anything dark.

The alarm bell is thus drawn because in addition to what has existed for a long time (roads), we are currently witnessing a dangerous turn because many buildings (even old) are painted in black, blue, brown etc. or having large windows, which makes them hot following the absorption of solar radiation, they then emit a type of far infrared radiation, naturally stopped by greenhouse gases in the same way as the infrared radiation emitted by the planet earth day and night. Thus global warming is increased. It remains to quantify this increase. What is certain, however small, that is its effect is harmful, and hence there is reason to act to limit the extent of the artificial surfaces that emit it.

If the fraction of the mass of $\mathrm{CO}_{2}$ compared to that of the atmospheric gas that surrounds the earth is of the order of 10-7, however, all the international conventions point to $\mathrm{CO}_{2}$ as the cause of global warming because it plays the role of a greenhouse gas (COP 21 and 22). By analogy, it seems to us necessary to consider the part of the infrared radiation emitted by the artificial surfaces vis-à-vis the radiation emitted naturally by the earth; because moreover, it is emitted by surfaces at much higher temperatures, where the energy emittance is double. Moreover, in the future the extent of these surfaces increases with the extent of cities.

Global warming due to the greenhouse effect is therefore not only $\mathrm{CO}_{2}$ emissions but also infrared radiation not only emitted naturally by the earth, but also artificially by human constructions of dark color. Such an increase deserves, in our opinion, to be considered before it is too late because urban planning is only increasing as a result of population growth and in the absence of laws that limit the phenomenon especially in countries with strong sunshine.

\section{Bibliographic Study}

Global warming is a reality that no one can deny, as shown in Figures 1 and 2 below:

In 1909, Robert Williams Wood shows that contrary to popular belief, the blockage of infrared radiation by glass is not the main mechanism that explains the operation of a greenhouse. Therefore the scientific term, adopted by the IPCC, used to describe the influence of the components of the atmosphere blocking infrared radiation on the Earth's heat balance is radioactive forcing and not greenhouse effect.

He demonstrated in 1909 the erroneous nature of the explanation of the greenhouse effect by the trapping of infrared rays by glass; simply by replacing ordinary glass with halite transparent to these rays (the explanation lies almost exclusively in the blocking convection). 
Citation: Romdhane Ben Slama (2018) Impact of the Artificial Surfaces Sunk on the Global Warming by the Absorption of the Solar Radiation and the Albedo Coefficient Modification. J Climatol Weather Forecasting 6: 230. doi:10.4172/2332-2594.1000230

Page 2 of 5

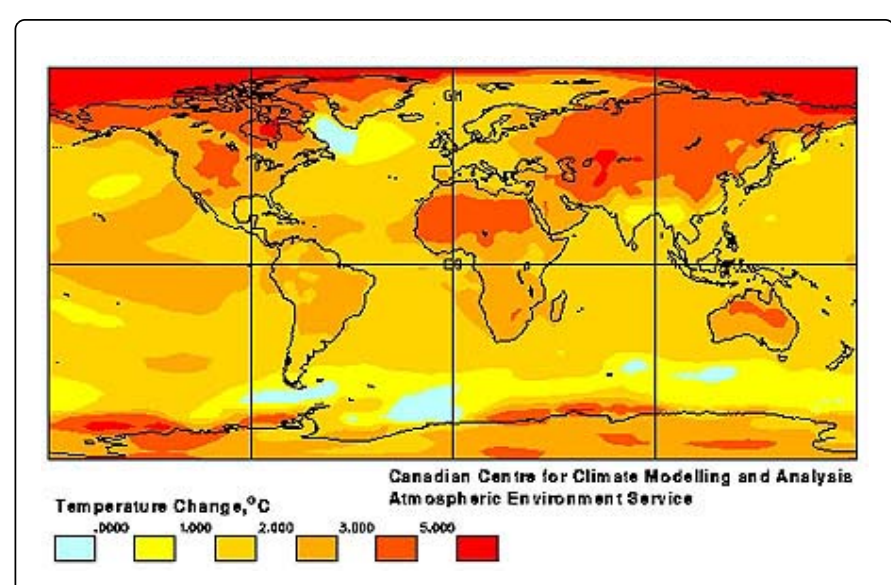

Figure 1: Annual Mean Temperature Change: 2040-2060 minus 1970-1990 [1].

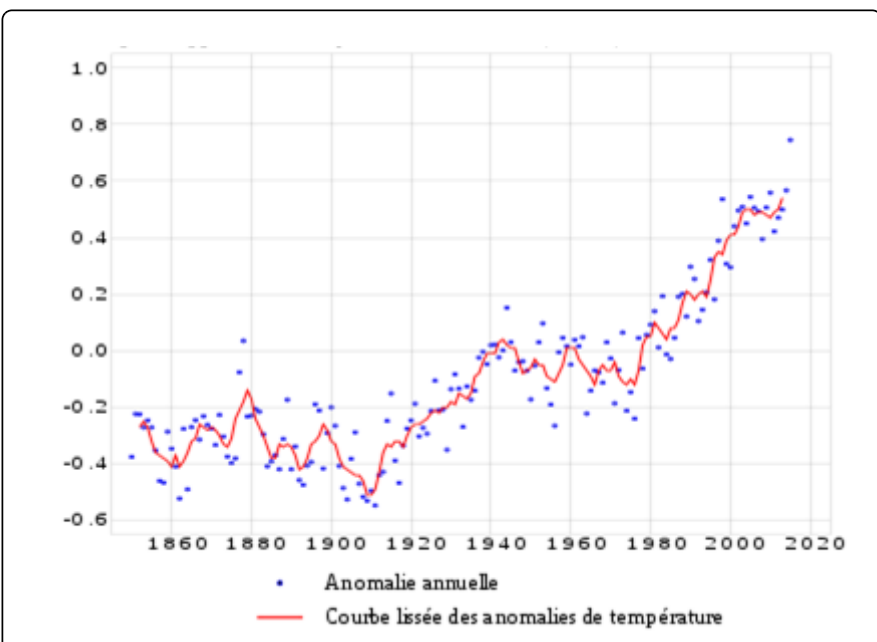

Figure 2: Annual Mean Temperature compared to the 1961-1990 average [1].

Let's say it's true in a greenhouse, the warming is both the imprisonment of infrared rays and the reduction of convective losses because the greenhouse is hermetically closed; this is how, for the case of solar water collectors, there are those that are under vacuum to completely eliminate convective losses. Note that for agricultural greenhouses, farmers open the doors to create a draft in case of overheating in the presence of solar radiation. These are not the only ones responsible for warming a greenhouse, but it is the cover that mitigates the convective losses of the greenhouse with the outside ambient air. There are indeed double-glazed greenhouses in glass or plastic. Figure 3 shows that if there is no greenhouse effect (natural) the earth would be freezing. However, human activities have generated a lot of greenhouse gas emissions, which has significantly magnified the greenhouse effect and caused global warming.

Ben Slama [2-5] explains that while it is undeniable that the increase in $\mathrm{CO} 2$ emissions and its equivalents is causing the greenhouse effect, it should be noted that $\mathrm{CO} 2$ only stops far-infrared radiation, not the visible radiation for example. However, many human-built (roads, buildings, etc.) and dark-colored construction surfaces absorb solar radiation and re-emit it into the far-infrared spectrum to which greenhouse gases are opaque; the radiation is returned to the earth causing global warming.

On the bibliographic illustration side, some authors mention the link between infrared radiation emitted by the surfaces of internal and external buildings [6]. Other authors evoke the close link between radiation received and emitted by the earth $[7,8]$ and global warming [9].

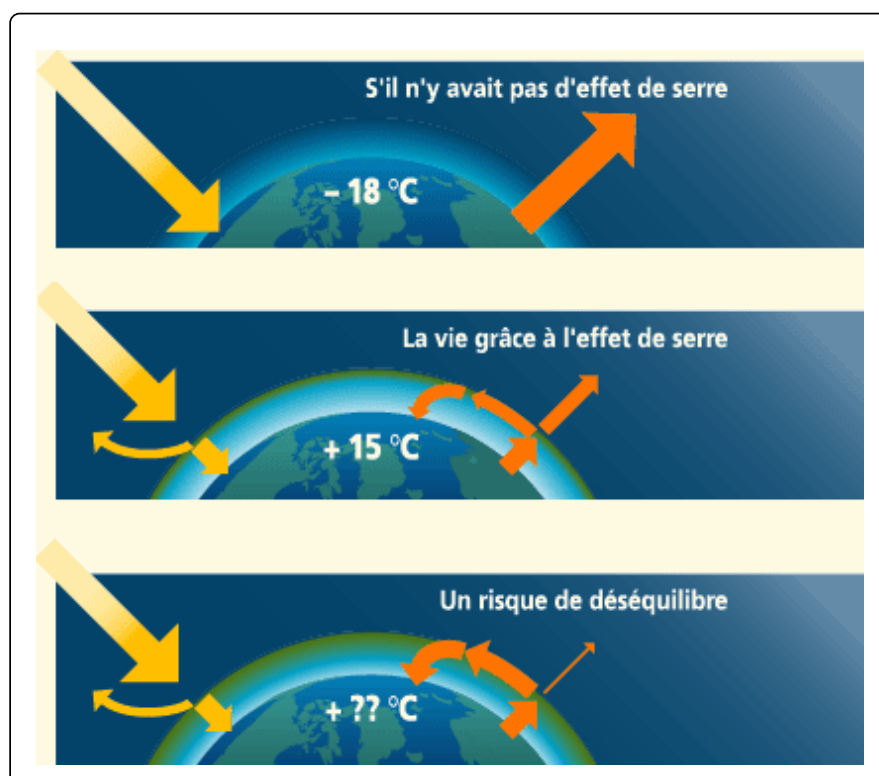

Figure 3: Global warming principle a) if there is no greenhouse effect b) with the greenhouse effect c) with the ad of greenhouse effect gazes.

Kasztendeuch and Najjar [10] as well as Koncou et al [11] evoke the city atmosphere interaction in the perception of solar radiation, the projection of the shadow and the night warming especially in summer. A study by Ben Slama [12] shows the perception of solar radiation according to their impact on the walls of buildings for example.

In fact, the atmosphere, the oceans and the surface of the continents absorb solar radiation (short wavelengths: 0.25 to 2.5 micrometers). Thus, the Earth (surface and atmosphere) emits infrared radiation (between 5 and 100 micrometers). This radiation is emitted to space and therefore represents a loss of energy for the Earth. The overall balance is therefore zero. However, in the presence of GHGs, this farinfrared radiation is not transmitted to space $[13,14]$ but sent back to the earth causing its warming, hence the climate change of which humanity is well aware (CF. COP 21 in Paris, November 2015 and COP 22 in Marrakech, November 2016).

The infrared radiation of the Earth can be measured by satellites equipped with sensitive sensors to this radiation and redirected towards the Earth. The image in Figure 4 represents an average of the measurements taken during the month of March 2001. 
Citation: Romdhane Ben Slama (2018) Impact of the Artificial Surfaces Sunk on the Global Warming by the Absorption of the Solar Radiation and the Albedo Coefficient Modification. J Climatol Weather Forecasting 6: 230. doi:10.4172/2332-2594.1000230

Page 3 of 5

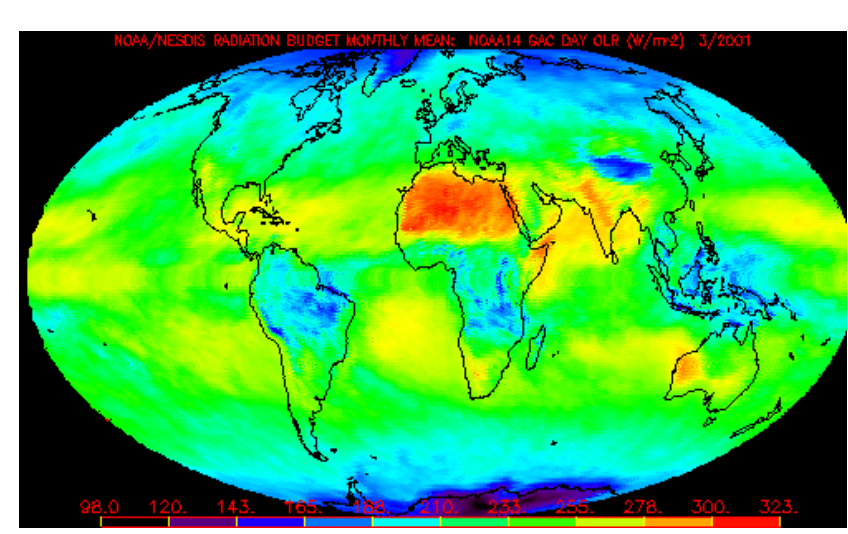

Figure 4: IR radiation emitted by the earth [6].

The IPCC reports evoke the impact of albedo modification on global warming, indicating that the melting of the ice of the poles would lead to a decrease in albedo and consequently a greater absorption of solar radiation and therefore warming. However it does not evoke the variation of the albedo of the constructions (roads and buildings) in the sunny countries!!!! which are growing more and more. By prestige search people choose dark colors for buildings. For cold countries, with low tau of sunshine, the dark colors of the artificial structures of cities have little effect on infrared emissions; which is not the case for very sunny countries.

\section{Analogy Between a Solar Collector and Our Planet Earth}

Being personally a specialist in solar energy, thermal conversion, and to understand the purpose of this article, it is more explicit to start with a reminder of the thermal capture of solar radiation, with which I find that there is a similarity with the theme treated here since both are concerned by the greenhouse effect, but one favorably and the other adversely.

The principle of solar collectors is well known. They consist of an absorber (black), glazing (to create the greenhouse effect and causing the absorber to warm up), and thermal insulation to conserve heat (Figure 5).

To heat, it is necessary to place a window which lets the solar spectrum pass and which reflects thereafter the infrared radiation emitted by the absorber; moreover, black; this is how Far Infrared IR is produced. Against example: Imagine now that the absorber is white, it will therefore directly reflect the incident solar radiation, which will be possible to cross the window "selective"; so there will be no heating up in the solar collector! By analogy, these observations of the phenomenon of the greenhouse effect at the scale of the solar collector can be extrapolated on the planet earth scale concerning its reception of the solar radiation and it's heating by the GHGs. Figure 6 shows this phenomenon: transmission of solar radiation and reflection of infrared radiation.

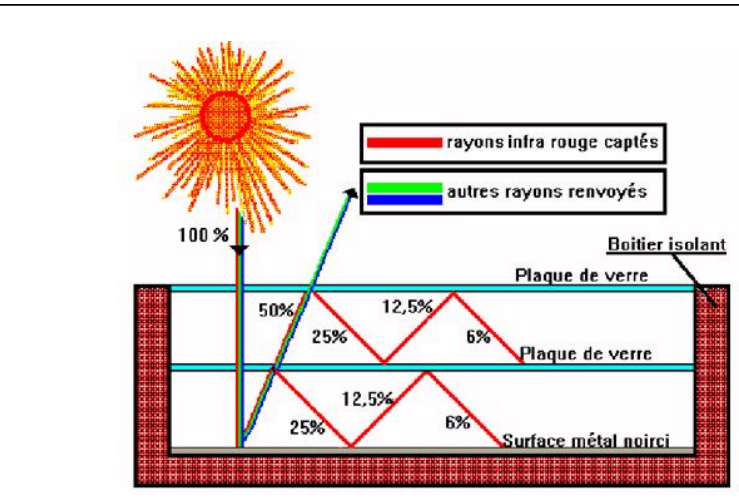

Figure 5: Constitution of a solar collector with double glazing. Creation of the greenhouse effect.

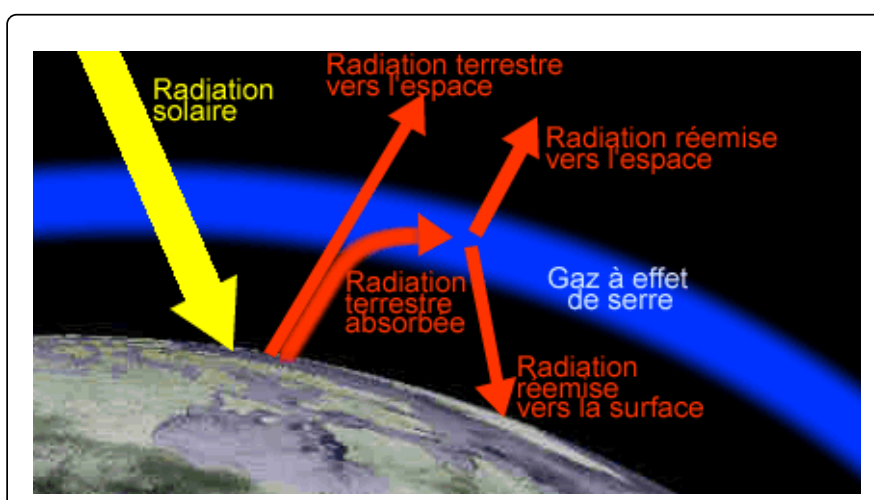

Figure 6: Earth, sun, Infrared emissions and global warming by GHGs [13].

\section{Artificial Elements Impact in Infrared Emissions and Global Warming}

Evolution of the area of artificialized areas: in the year 2000, the global urban coverage represented $0.5 \%$ of the total land area. In 2030 , the urban space will have tripled in area, ie 1.2 million $\mathrm{km} 2$ of additional surface area (in all 1.8 million $\mathrm{km}^{2}$, i.e. $1.5 \%$ of the total land area). In 2050, cities are home to $65 \%$ of the world's 9.5 billion people. In France, artificialized areas (tarred, built) occupy 4.9 million hectares in 2010 , i.e. nearly $9 \%$ of the metropolis.

\section{Climate Impact}

During the day, in the presence of clear sky sunshine, to the terrestrial radiation emissions in the IR spectrum towards the atmosphere, is added the infrared radiation emitted by artificial structures of dark color such as roads, cities, cars and even the clothes of individuals who emit in the same order of magnitude of wavelength; this is the latent object of this reflection and the writing of this article $[15,16]$.

Obviously this only concerns the surplus daytime radiation due to artificial elements that absorb solar radiation (Figures 7-9). 
Citation: Romdhane Ben Slama (2018) Impact of the Artificial Surfaces Sunk on the Global Warming by the Absorption of the Solar Radiation and the Albedo Coefficient Modification. J Climatol Weather Forecasting 6: 230. doi:10.4172/2332-2594.1000230

Page 4 of 5

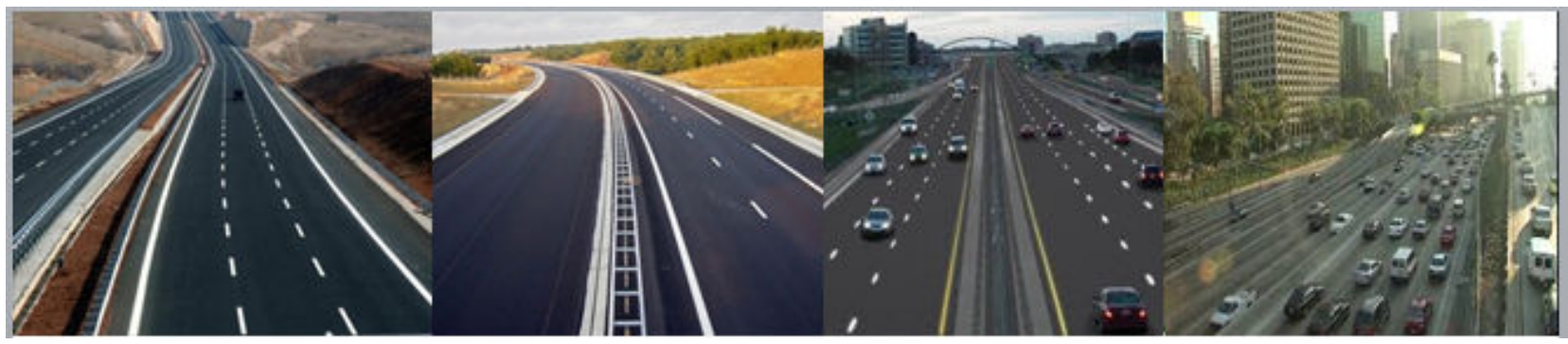

Figure 7: Dark colored roads and pavements absorb sunlight and emit in the far infrared.

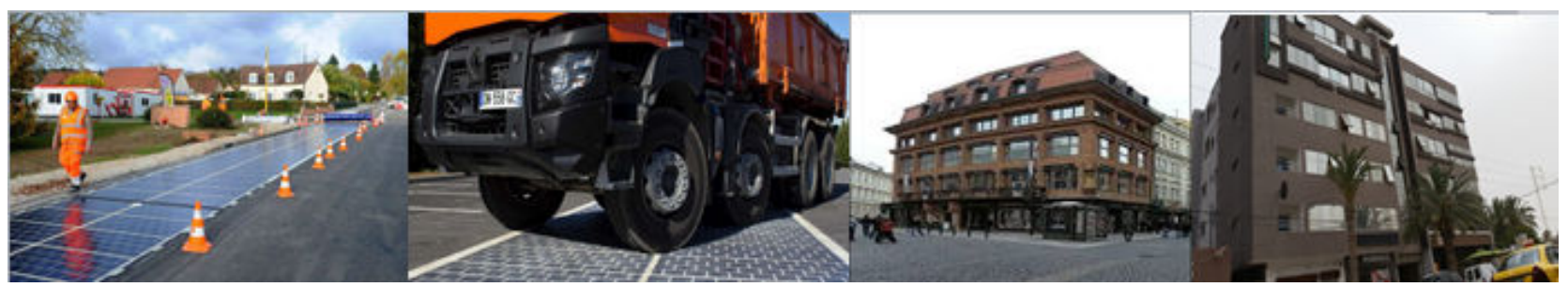

Figure 8: Dark-colored buildings and their emissions IR.

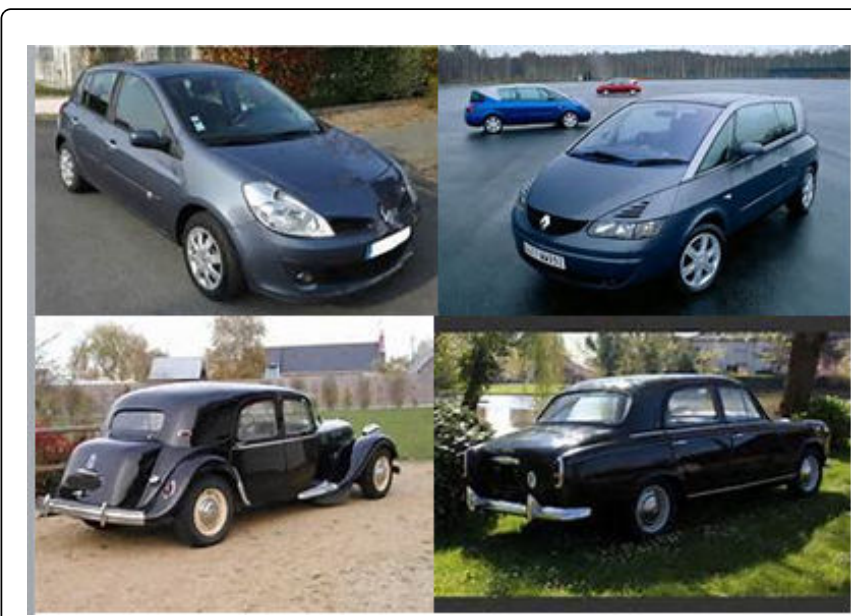

Figure 9: The dark colors of vehicles and their infrared emissions.

Thus, $\mathrm{CO}_{2}$ plays the role of greenhouse gas GHG only if it is opposed to infrared radiation emitted by the surface of the earth, during the crossing and the penetration of the atmosphere, a natural way. This IR radiation is of the distant type. Added to this are the IR emissions of the dark and therefore warm surfaces of artificial structures built by man on the earth. It is therefore urgent to limit the area of these emitting surfaces and to avoid their expansion.

The power radiated by a matt surface, heated by the sun and according to its temperature is given by: $\mathrm{P}=\sigma . \mathrm{T} 4$

And, the corresponding average wavelength is given by: $\lambda$ moy

It should be noted that the power emitted at $70^{\circ} \mathrm{C}$ is almost twice that at low temperature $\left(20^{\circ} \mathrm{C}\right)$. Surfaces should not be heated by the effect of the sun. However, the sun cannot be easily avoided. On the other hand, it is possible to avoid its absorption by the use of clear and non-dark surfaces. Indeed, the absorption coefficient of solar radiation by a surface depends on its color, as shown in Figure 10.

In addition, the heating of the surfaces following the absorption of solar radiation has several harmful consequences:

- Creates significant thermal differences

- Cause premature aging of the finishes

- Causes blistering (if significant wood moisture)

- Causes scaling

- Promotes resin flows

- Promotes dimensional variations

\begin{tabular}{|l|l|l|l|l|l|l|}
\hline Surface Temperature & $\mathbf{2 0 ^ { \circ } \mathbf { C }}$ & $\mathbf{3 0 ^ { \circ } \mathbf { C }}$ & $\mathbf{4 0 ^ { \circ } \mathbf { C }}$ & $\mathbf{5 0 ^ { \circ } \mathbf { C }}$ & $\mathbf{6 0 ^ { \circ } \mathbf { C }}$ & $\mathbf{7 0}^{\circ} \mathbf{C}$ \\
\hline Average wavelength of radiation & 9.89 & 9.56 & 9.25 & 8.97 & 8.70 & 8.44 \\
\hline $\begin{array}{l}\text { Power of radiation causing the greenhouse effect } \\
\left(\mathrm{W} / \mathrm{m}^{2}\right)\end{array}$ & 417 & 478 & 544 & 617 & 697 & 785 \\
\hline
\end{tabular}

Table 1: Showing Surface temperature at different wavelength of radiation and greenhouse effect. 
Citation: Romdhane Ben Slama (2018) Impact of the Artificial Surfaces Sunk on the Global Warming by the Absorption of the Solar Radiation and the Albedo Coefficient Modification. J Climatol Weather Forecasting 6: 230. doi:10.4172/2332-2594.1000230

Page 5 of 5

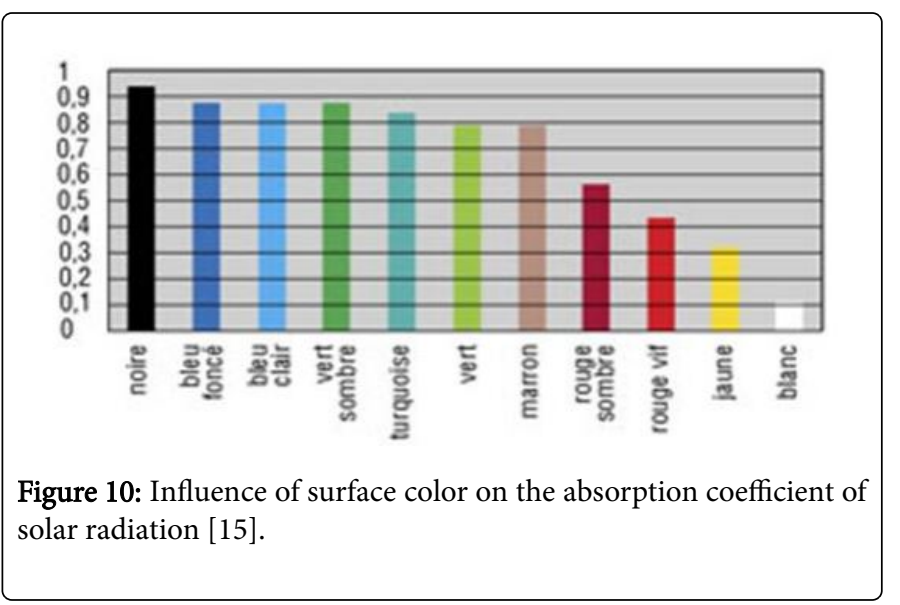

\section{Conclusion}

The infrastructure of the cities (roads and buildings) but also the roads and the vehicles participate, especially in the countries with strong sunshine to modify the temperature of the globe in the sense that, the day, being exposed to the solar radiation, their surfaces if they are dark absorb all the solar radiation and re-emit in the far infrared spectrum, all the more energetic as the temperature is high, so that the surface is dark (black in particular). However, far infrared radiation does not cross the atmosphere and therefore favors radioactive forcing and consequently the greenhouse effect. In our warm countries, and more than in the cold Nordic countries, it is urgent to stop the expansion of the use of dark colors for any surface exposed to the sun; walls, roads, roadways, vehicles and even our clothes.

While limiting greenhouse gas emissions is of primary interest to industrialized countries, hot countries are also implicated in the greenhouse effect in reducing dark surfaces exposed to the sun.

\section{References}

1. https://fr.wikipedia.org/wiki/R\%C3\%A9chauffement_climatique\#/ media/File:EcartsTempSurface2015.svg

2. Slama BR (2016) Green House Effect vs. Infrared Radiation Emissions. Journal of Climatology \& Weather Forecasting 4: 1 .
3. Slama BR (2017) Effet de serre vs émissions terrestres de rayonnement infrarouge : l'effet de serre n'est pas du qu'au dégagement des Gaz à Effet de Serre. Colloque 604. Congres de l'ACFAS 85éme édition, sur le thème : « Regards croisés sur l'adaptation aux changements climatiques dans le transport terrestre : Quelles formes, insuffisances et nouvelles pistes? Université McGill, Montréal, Quebec Canada.

4. Slama BR (2017) Role of the dark surfaces of cities on the greenhouse effect increase. Int.Conf.on Sustainible development» Ottawa, Ontario Canada, 9-10 August 2017. Visioconference.

5. Slama BR (2017) Effet de serre vs émissions terrestres de rayonnement infrarouge. L'effet de serre n'est pas du qu’au dégagement des Gaz à effet de serre. Eau-Société-Climat'2017 (ESC-2017) Impacts Anthropiques et Climatiques sur la Variabilité des Ressources en Eau. Hammamet le.

6. Slama BR (2017). L'Effet de serre et les radiations infrarouges des zones urbaines et goudronnées sombres. International Congress on Energetic and Environmental Systems (IEES-2017).

7. Szargut JT (2003) Anthropogenic and natural exergy losses (exergy balance of the Earth's surface and atmosphere). Energy 28: 1047-1054.

8. Michel Petit (2003) The greenhouse effect, impacts and possible solutions: overall credibility? C. R. Geoscience 335: 497-501.

9. Knox RS (1999) Physical aspects of the greenhouse effect and global warming. American Journal of Physics 67: 1227.

10. Kounkou (2012) Méthodologie pour la quantification de limpact d’aménagements urbains sur un climat urbain modifie. Climatologie, numéro spécial 'Climats et changement climatique dans les villes'.

11. Slama BR (2007) Apports solaires dans le bâtiment en Tunisie - Approche bioclimatique. 10éme Colloque de l'Association Internationale de Climatologie AIC 20: 99-104.

12. Kokkila SI, Bera PP, Francisco JS, Lee TJ (2012) A group increment scheme for infrared absorption intensities of greenhouse gases. Journal of Molecular Structure 1009: 89-95.

13. http://www.notrepflanete.finfo/actuaflfites/actu_2695_spectrophotometrfie _finfrarouge_effet_serre.php

14. http://planet-terre.ens-lyon.fr/article/bilan-radiatif-terre3.xml

15. Ming T, Richter R, Liu W, Caillol S (2014) Fighting global warming by climate engineering: Is the Earth radiation management and the solar radiation management any option for fighting climate change? Renewable and Sustainable Energy Reviews 31: 792-834.

16. https://fr.wfikfipedfia.org/wfikfi/R\%C3\%A9chauffement_cflfimatfique \#Hypoth.C3.A8se_d.27un_effet_de_serre_addfitfionnefl 